\title{
Analisis Ekologi Lamun Di Pulau Rao, Kecamatan Morotai Selatan Barat, Kabupaten Pulau Morotai
}

\section{Analysis of Seagrass Ecology in Rao Island, Morotai Sub-District South West, Morotai Island}

\author{
Sandra Hi Muhammad*1, Iswandi Wahab ${ }^{2}$, dan Ismawati Alican ${ }^{3}$ \\ 1,2,3Fakultas Perikanan dan Ilmu Kelautan, Universitas Pasifik Morotai, Maluku Utara, Indonesia
}

Korespondensi : iswandi.fpik@gmail.com

\begin{abstract}
ABSTRAK
Salah satu sumberdaya alam yang berperan sebagai produsen primer yaitu ekosistem lamun. Lamun adalah tumbuhan berbunga (Angiospermae) yang mampu beradaptasi secara penuh di perairan yang salinitasnya cukup tinggi atau hidup terbenam di dalam air. Tujuan penelitian menganalisis Komposisi jenis, dan persentase tutupan lamun. Metode penelitian mengunakan transek kuadran 1x1 m. Analisis data yang dilakukan secara deskriptif dan ditampilkan dalam bentuk diagram dan tabel. Hasil pengambilan data komposisi jenis lamun di 3 stasiun pengamatan menunjukan bahwa ada perbedaan di mana yang tertinggi di temukan pada stasiun III sebanyak 5 jenis dengan jumlah 5 individu jenis, kemudian yang tertinggi ke dua pada stasiun II ditemukan 3 jenis dengan jumlah 3 individu, sedangkan yang paling terendah yaitu pada stasiun I sebanyak 2 jenis dengan total 5 individu. Hasil yang di temukan persen penutupan lamun tertinggi berada pada stasiun I sebesar $36 \%$ dan terendah pada stasiun II sebesar $31 \%$.
\end{abstract}

Kata kunci : lamun, komposisi, penutupan, pulau rao

\begin{abstract}
One of the natural resources that acts as a primary producer is the seagrass ecosystem. Seagrass is a flowering plant (Angiosperms) that is able to fully adapt to waters with high salinity or live immersed in water. The research objective was to analyze the species composition, and the percentage of seagrass cover. The research method used the transect quadrant $1 x 1 \mathrm{~m}$. Data analysis was carried out descriptively and displayed in diagrams and tables. The results of data collection on the composition of seagrass species at 3 observation stations showed that there were differences, the highest was found at station III with 5 species, then the second highest at station II was found 3 species with 3 species, while the second highest was found at station II. the lowest is at station I as many as 2 types with a total of 5 individuals. The results found that the highest percentage of seagrass cover was at station I at $36 \%$ and the lowest was at station II at $31 \%$.
\end{abstract}

Keywords : seagrass, composition, cover, rao island 


\section{PENDAHULUAN}

Salah satu sumberdaya alam yang berperan sebagai produsen primer yaitu ekosistem lamun. Lamun adalah tumbuhan berbunga (Angiospermae) yang mampu beradaptasi secara penuh di perairan yang salinitasnya cukup tinggi atau hidup terbenam di dalam air. Lamun memiliki rizhoma, daun, dan akar sejati (Nontji, 1987; Nasmia, 2012). Komunitas lamun memegang peranan penting baik secara ekologis, maupun biologis di daerah pantai dan estuari.

Ekosistem lamun merupakan salah satu ekosistem bahari yang produktif, selain sebagai sumber produktifitas primer di perairan juga memiliki arti penting bagi hewan yang hidup di area padang lamun, diantaranya menyediakan daerah perawatan (nursery area) bagi banyak spesies yang menyokong perikanan laut lepas, dan untuk habitat lainnya, seperti rawa payau, terumbu karang, dan hutan mangrove (Bengen, 2004). Menurut Kiswara (1985), jenis lamun dipengaruhi oleh faktor tempat tumbuh dari lamun tersebut, beberapa faktor yang mempengaruhi lamun di antaranya meliputi kedalaman, tipe substrat, kecerahan, arus. Selain itu morfologi lamun juga berpengaruh terhadap kerapatan jenis lamun.

Substrat sangat berperan menentukan kehidupan lamun yaitu, sebagai media tumbuh lamun agar tidak terbawa arus dan gelombang, serta sebagai media pendaur zat hara. Perbedaan komposisi jenis substrat dapat menyebabkan perbedaan komposisi jenis lamun, yang tumbuh (Wahab et al, 2017). Hal ini didasari oleh pemikiran Hasanuddin (2013) bahwa perbedaan komposisi ukuran butiran pasir akan mempengaruhi ketersediaan nutrisi bagi pertumbuhan lamun dan proses dekomposisi dan meneralisasi yang terjadi di dalam substrat (Kiswara, 1992).

Pola hidup lamun sering berupa hamparan sehingga dikenal dengan istilah padang lamun (seagrass bed), yaitu hamparan vegetasi lamun yang menutupi suatu area pesisir atau laut dangkal, terbentuk dari satu jenis atau lebih dengan kerapatan padat atau jarang. Habitat tempat hidup lamun adalah perairan dangkal agak berpasir dan sering juga dijumpai di terumbu karang dan mangrove (Bengen DG. 2001). Selain itu, padang lamun juga membantu mengurangi laju perubahan iklim dengan menyerap emisi karbondioksida. Padang lamun juga dapat menahan gelombang, serta menangkap dan menstabilkan sedimen, sehingga air menjadi lebih jernih. 
Pulau Rao merupakan pulau kecil yang terpisah dari daratan Pulau Morotai yang terletak di sebelah selatan barat dengan jarak sekitar $40 \mathrm{~km}$ dari pusat kota. Pulau ini terdapat habitat lamun dan diantara habitat mangrove dengan terumbu karang, dan berasosiasi diantara ketiganya. Adanya asosiasi ini menjadikan Pulau sangat kompleks dengan keberagaman sumber daya ekosistem. Belum adanya informasi terkait kondisi ekologi lamun disekitar perairan ini, mendorong dilakukan penelitian analisis ekologi lamun di Pulau Rao Kecamatan Morotai Selatan Barat.

\section{METODE PENELITIAN}

Penelitian ini dilakukan di perairan Pulau Rao, Kecamatan Morotai Selatan Barat, Kabupaten Pulau Morotai pada bulan januari (Gambar 1), dengan posisi Geografis Stasiun I. N. $02^{\circ} 18^{\prime} 23.4^{\prime \prime}$ E. $128^{\circ} 11^{\prime} 19.1^{\prime \prime}$ Stasiun II. N. 02 $18^{\prime}$ 27.1" E. $128^{\circ} 11^{\prime} 18.3^{\prime \prime}$ Stasiun III. N. $02^{\circ} 18^{\prime} 29.9^{\prime \prime}$ E. $128^{\circ} 11^{\prime} 13.7^{\prime \prime}$.

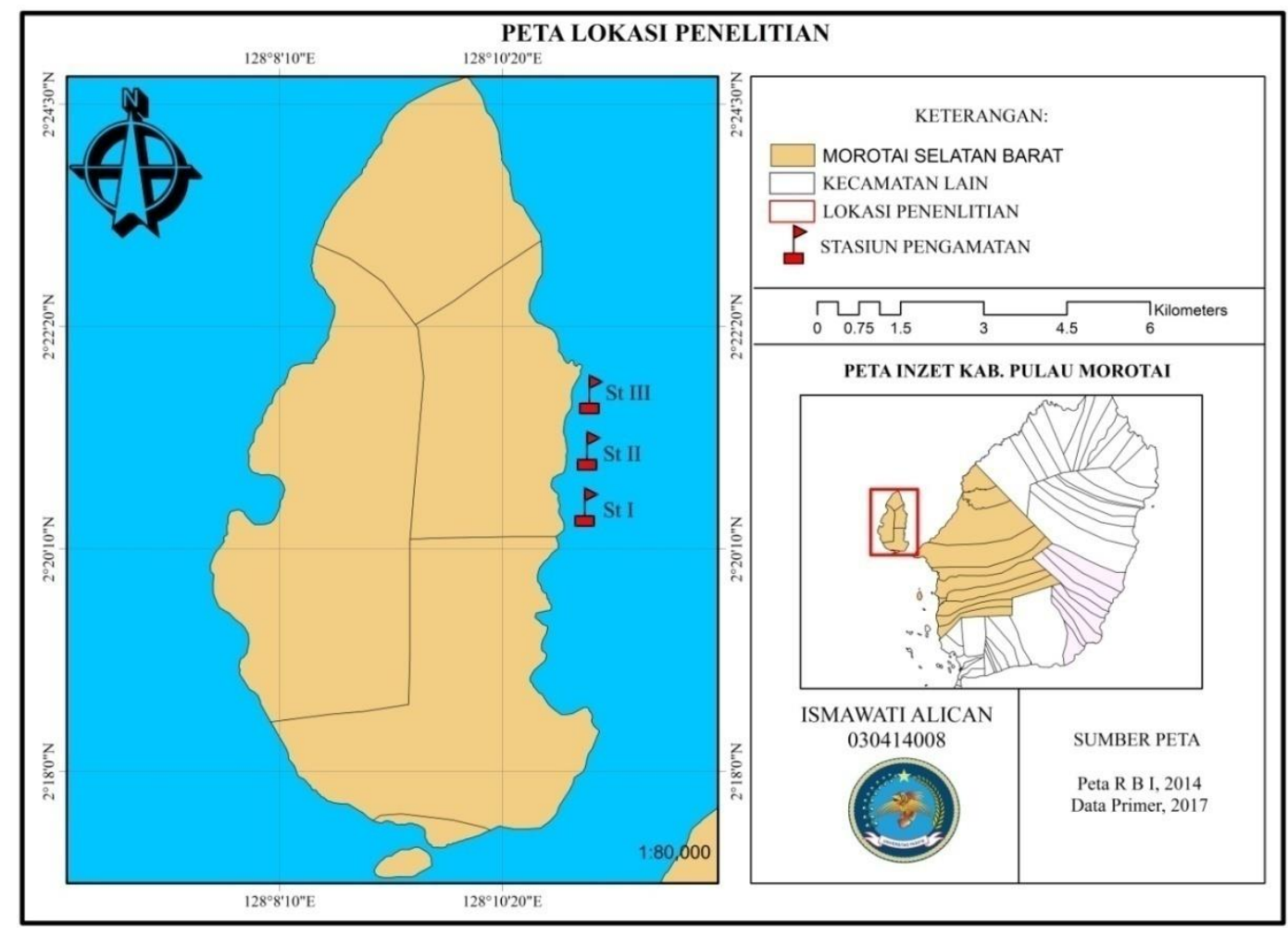

Gambar 1. Peta Lokasi Penelitian 


\section{Alat dan Bahan}

Alat dan bahan yang di gunakan pada pengambilan sampel lamun dan parameter pendukung (tabel 1).

Tabel 1. Alat dan bahan yang digunakan pada penelitian.

\begin{tabular}{clcl}
\hline NO & \multicolumn{1}{c}{ Alat dan Bahan } & Jumlah Satuan & \multicolumn{1}{c}{ Kegunaan } \\
\hline 1 & Transek Kuadran Ukuran 1x1 m. & 1 buah & Sebagai batasan pengamatan \\
2 & Roll Meter. & 1 buah & Mengukur jarak transek \\
3 & GPS. & 1 buah & Menentukan posisi \\
4 & Papan Jalan, Pensil, Penggaris $300 \mathrm{~cm}$. & 1 buah & Menulis data hasil pengamatan \\
5 & Lembaran Identifikasi Lamun. & 3 lembar & Sebagai acuan literatur \\
6 & Refraktometer. & 1 buah & Mengukur salinitas \\
\hline
\end{tabular}

\section{Teknik Pengambilan Data}

Pengambilan sampel dilakukan dengan menggunakan tehnik transek garis.kuadran berukuran 1x1 m dan jarak dari transek satu ketransek berikutnya $15 \mathrm{~m}$ sedangkan jarak stasiun satu ke stasiun berikutnya $50 \mathrm{~m}$. Dengan membagi lokasi penelitian kedalam 3 stasiun yang setiap stasiunnya terbagi menjadi tiga titik. Letak dari transek sangat menentukan,stasiun pengambilan sampel diawali dengan menentukan letak dari transek garis yang telah ditentukan dan dicatat letaknya,stasiun dimulai dari daerah yang paling dekat dengan pantai.dan mencatat titik pertama dimulai sedangkan stasiun kedua, dan seterusnya mempunyai jarak yang sama dan letaknya paralel mengikuti arah transek garis tegak lurus kelaut.

Jarak antara stasiun ini disesuaikan dengan tipe komunitas lamun apabila mempunyai jenis yang beragam hendaknya jaraknya dipersempit sedangkan apabila jenisnya homogen jarak yang sering digunakan 15-20 m. Titk transek kuadran sedikitnya harus dilakukan 3x pada tiap-tiap stasiun yang letaknya tegak lurus dengan garis pantai. Pengambilan contoh titik ini akan semakin banyak pada setiap stasiunnya apabila sebaran lamun ini memanjang sampai kelaut (Setiobudiandi et al, 2009). 


\section{Pengambilan Data Lamun}

\section{Komposisi Jenis Lamun}

Komposisi jenis lamun diketahui dengan membandingkan jumlah individu masingmasing jenis dengan total individu seluruh jenis dimodifikasi dari Fachrul (2007):

$$
K j=\frac{n i}{N} \times 100 \%
$$

Dimana:

$$
\begin{aligned}
& K j=\text { Komposisi jenis vegetasi lamun }(\%) \\
& n i=\text { Jumlah individu setiap jenis vegetasi lamun. } \\
& N=\text { Jumlah individu seluruh jenis vegetasi lamun. }
\end{aligned}
$$

\section{Persentase Tutupan Lamun}

Tutupan lamun menyatakan luasan area yang tertutupi oleh lamun. Persentase tutupan lamun ditentukan berdasarkan rumus Shannon-Weaner.

$$
C=M_{i} X F_{i} / f
$$

Dimana:

$$
\begin{aligned}
& C=\text { nilai persentase tutupan lamun }(\%) \\
& M_{i}=\text { nilai tengah kelas tutupan ke-i } \\
& F_{i}=\text { Frekuensi munculnya kelas tutupan ke-i } \\
& F=\text { Jumlah total frekuensi tutupan kelas. }
\end{aligned}
$$

\section{Analisis Data}

Analisis data yang dilakukan untuk mengetahui beberapa parameter ekologi vegetasi lamun, dilakukan secara deskriptif dan ditampilkan dalam bentuk diagram dan tabel. 


\section{HASIL DAN PEMBAHASAN}

\section{Deskripsi Umum Lokasi Penelitian}

Perairan Pulau Rao ini terletak di Kecamatan Morotai Selatan Barat Kabupaten Pulau Morotai. Bagian utara Pulau Rao berbatasan dengan perairan Desa Wayabula, bagian timur berbatasan dengan Desa Aru Burung, bagian selatan berbatasan dengan Desa Leo-Leo, dan bagian barat berbatasan langsung dengan Pulau Saminyamau. Perairan ini memiliki tipe air laut yang jernih dan tipe pantai pasir putih dan memiliki substrat berpasir, karang hidup, dan karang mati.

\section{Parameter Lingkungan Perairan}

Berdasarkan hasil pengukuran parameter lingkungan fisika kimia air laut yang di lakukan di lokasi Praktek Kerja Lapangan (PKL) dari 3 stasiun pengamatan PKL dapat dilihat pada tabel 2 .

Tabel 2. Parameter Lingkungan Perairan dilokasi Penelitian

\begin{tabular}{llccc}
\hline \multirow{2}{*}{ No } & \multirow{2}{*}{ Parameter } & \multicolumn{3}{c}{ Stasiun } \\
\cline { 3 - 5 } & & I & II & III \\
\hline 1 & Salinitas (\%) & 33 & 34 & 35 \\
2 & Kecerahan (\%) & 100 & 100 & 100 \\
3 & $\mathrm{pH}$ & 9,5 & 9 & 9 \\
4 & Arus (m/d) & 41,3 & 40,6 & 27,1 \\
5 & Kedalaman (m) & 1 & 1 & 1 \\
6 & Substrat & Pasir karang & Pasir karang & Pasir halus \\
\hline
\end{tabular}

Nilai salinitas yang di dapat berdasarkan hasil pengukuran pada ke tiga stasiun berkisar 33-35\%. Kisaran salinitas yang optimal untuk pertumbuhan lamun antara 24-35 \%o (Hilman et al. 1989 dalam Zulkifli 2003). Menurut Nontji (2005) bahwa setiap lamun memiliki kemampuan yang berbeda untuk beradaptasi dengan salinitas perairan laut. Pada pengamatan kecerahan disetiap stasiun di Pulau Rao menunjukkan nilai yang sama yaitu $100 \%$, yang berarti bahwa penyinaran cahaya matahari mencapai dasar perairan. Semakin rendah intensitas matahari yang masuk dalam perairan mengakibatkan semakin 
rendah laju fotosintesis. Padang lamun membutukan cahaya matahari untuk membantu proses fotosintesis.

Kedalaman perairan di semua stasiun penilitian yang di dapat adalah masing-masing 1 meter kedalaman perairan yang terukur pada setiap lokasi merupakan kedalaman ideal bagi lamun karena proses fotosintesis dapat berlangsung. Sedangkan kisaran $\mathrm{pH}$ yang diperoleh dalam penelitian ini tidak berbeda jauh pada setiap stasiun pengamatan yaitu pada stasiun II dan III nilai $\mathrm{pH}$ yang di dapat sebesar 9 pada stasiun I pH 9,5. Menurut Effendi (2000), air laut umumnya memiliki kisaran $\mathrm{pH}$ antara 7-8,5 dan menurut Dawso dalam Reswara 2010 lamun dapat tumbuh optimal jika berada dalam kisaran $\mathrm{pH}$ antara 7,5-8,5. Berdasarkan data yang diperoleh, nilai $\mathrm{pH}$ yang didapat berada dalam batas normal dan nilai $\mathrm{pH}$ tersebut menunjukkan bahwa kondisi perairan Pulau Rao memungkinkan bagi lamun untuk tumbuh optimal. Kecepatan arus yang diperoleh dalam penelitian ini adalah 41,3 m/dtk untuk stasiun I, 40,6 m/dtk untuk stasiun II, dan 27,1 $\mathrm{m} / \mathrm{dtk}$ untuk stasiun III. Produktivitas pada lamun juga dipengaruhi oleh kecepatan arus perairan. Menurut Laevastu dan Hayes 1981 dalam Merryanto 2000, rendahnya kecepatan arus sangat mendukung bagi pertumbuhan dan perkembangan lamun.

Pengukuran substrat pada stasiun 1, 2 dan 3 bahwa jenis substrat yang di temukan di ke 3 stasiun pengamatan cukup bervariasi yaitu pada stasiun I jenis substrat pada kuadran 1 pasir, kuadran 2 pasir berkarang dan kuadran 3 karang berpasir yang di tumbuhi oleh dua jenis lamun yaitu Thalassia hemprichii dan Halophila minor. Sedangkan untuk stasiun II, kuadran 1 pasir, kuadran 2 dan 3 pasir berkarang, terdapat 3 jenis lamun yaitu Halophila minor, Cymodocea rotundata dan Cymodocea serrulata. Dan untuk stasiun 3 pada kuadran 1 dan 2 terdapat jenis substrat pasir,untuk kuadran 3 terdapat pasir berkarang di temukan 5 jenis lamun yaitu Halophila minor, Halodule pinifolia, Enhalus acoroides, Cymodocea rotundata dan Thalassia hemprichii.

\section{Komposisi Jenis Lamun}

Jumlah jenis lamun yang ditemukan di lokasi penelitian sebanyak 6 jenis lamun yang tersebar di masing-masing stasiun penelitian. Stasiun III merupakan stasiun yang memiliki jenis lamun terbanyak yaitu 5 jenis lamun, dan untuk jenis lamun terbanyak ke 2 yaitu di temukan pada stasiun II yaitu sebanyak 3 jenis lamun dan yang paling sedikit di 
stasiun I yaitu hanya terdapat 2 jenis lamun (Tabel2). Sedangkan jenis lamun tersebar di ke tiga stasiun adalah Halophila minor dan jenis lamun yang paling sedikit di temukan adalah Halodule pinifolia dan Enhalus acoroides. Jenis lamun yang di temukan pada lokasi penelitian dapat di lihat pada tabel 3.

Tabel 3. Komposisi Jenis Lamun Yang ditemukan dilokasi penelitian

\begin{tabular}{cllcc}
\hline \multirow{2}{*}{ No } & Jenis Lamun & \multicolumn{3}{c}{ Stasiun } \\
\cline { 3 - 5 } & & I & II & III \\
\hline 1 & Thalassia hemprichii & $\sqrt{ }$ & - & $\sqrt{ }$ \\
2 & Halophila minor & - & $\sqrt{ }$ & $\sqrt{ }$ \\
3 & Cymodocea rotundata & - & - & $\sqrt{ }$ \\
4 & Enhalus acoroides & - & $\sqrt{ }$ & - \\
5 & Cymodecea serrulata & - & - & $\sqrt{ }$ \\
6 & Halodule pinifolia & - &
\end{tabular}

Ket $: \sqrt{ }:$ Ditemukan

- : Tidak ditemukan

\section{Sebaran Jenis Lamun Stasiun Pengamatan}

Komposisi jenis lamun yang di temukan padas tasiun I (satu) sebanyak 2 jenis dengan total sebanyak 5 individu (Gambar 2).

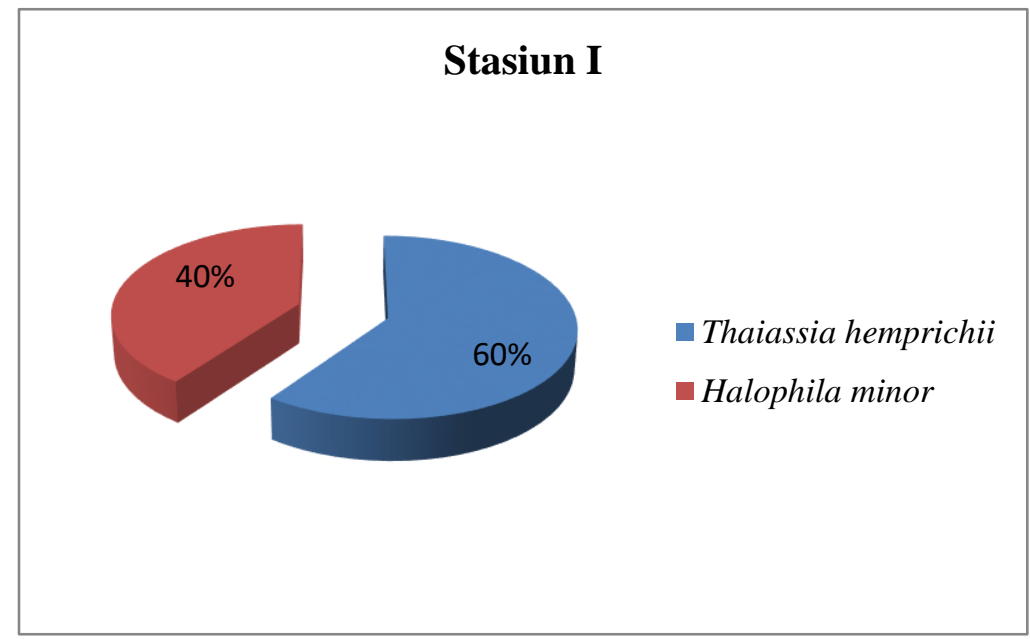

Gambar 2. Diagram jumlah komposisi jenis lamun pada stasiun I. 
Berdasarkan persentase komposisi jenis lamun (Gambar 2) untuk seluruh stasiun pengamatan, jenis yang cukup mendominasi yaitu Thalassia hemprichi. Fenomena ini didukung oleh penyataan Brouns dan Heijs (1991), bahwa padang lamun dangan vegetasi campuran umumnya terdiri dari sedikitnya 4 dari 7 jenis yaitu : Cymodocea rotundata, Cymodocea serrulata, Enhalus acoroides, Halodule uninervis, Halophila ovalis, Syringodium isoetifolium dan Thalassia hemprichii, tetapi dalam struktur komunitasnya selalu berasosiasi Enhalus acoroides dan Thalassia hemprichi yang selalu mendominasi.

Pada gambar 2 terlihat bahwa jumlah individu terbanyak pada stasiun I terdapat pada jenis Thalassia hemprichii sebanyak 3 individu dengan nilai komposisi tertinggi $60 \%$ jenis lamun Thalassia hemprichii ini dapat di temukan pada stasiun III juga tetapi dengan persentase yang sedikit, namun jenis Thalassia hemprichii ini tidak di temukan di stasiun II hal ini akibat adanya perubahan komposisi jenis yang di akibatkan pengaruh dari lingkungan fisika perairan, Thalassia hemprichii ini merupakan lamun yang memiliki bentuk mirip Cymodocea rotundata tetapi rhizoma beruas-ruas dan tebal memiliki garis coklat pada helaian daun. Sedangkan yang di temukan pada jenis Halophila minor sebanyak 2 individu dengan nilai komposisi $40 \%$ jenis Halophila minor dapat di temukan pada ketiga stasiun.

Pada stasiun II terlihat bahwa komposisi jenis lamun yang di temukan 3 jenis dengan jumlah total individu sebanyak 4 individu dengan nilai komposisi jenis lamun Halophila minor adalah 34\% dan untuk Cymodocea rotundata dan Cymodocea serrulata adalah masing-masing 33\% (Gambar 3).

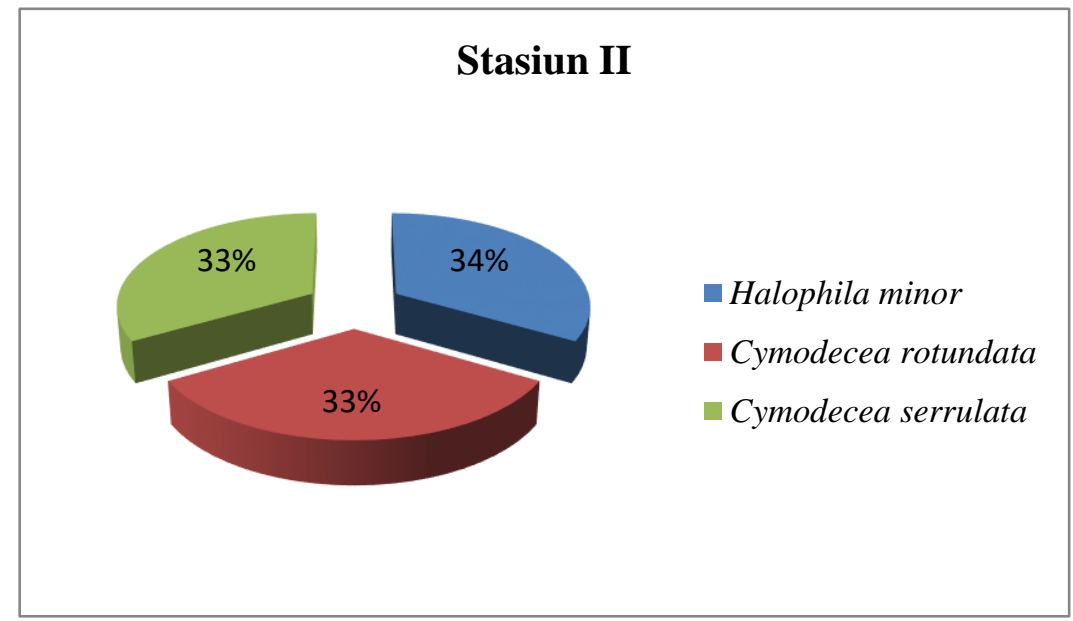

Gambar 3 diagram jumlah komposisi jenis lamun pada stasiun II. 
Halophila minor ini merupakan lamun yang memiliki bentuk daun oval, ukuran kecil, berpasangan dengan tangkai pada setiap ruas dari rimpang tulang daun kurang dari 8. Sedangkan untuk Cymodocea rotundata mempunyai bentuk tepi daun tidak bergerigi seludang daun menutupi sempurna,dan untuk Cymodocea serrulata mempunyai bentuk tepi daun bulat bergerigi seludang daun membentuk segitiga tidak menutupi sempurna. Hal ini dikarenakan adanya fenomena terjadinya penurunan jumlah jenis lamun di perairan Pulau Rao Kecamatan Morotai Selatan Barat yang di akibatkan pada stasiun II banyak di dominasi oleh karang mati.

Pada stasiun III terlihat bahwa komposisi jenis lamun yang di temukan sebanyak 5 jenis lamun dengan jumlah total 5 individu, nilai komposisi pada masing-masing jenis adalah 20\%. Jenis yang di temukan pada stasiun III yaitu jenis lamun Halodule pinifolia memiliki daun yang pipih panjang tetapi berukuran kecil dan satu urat tengah daun yang jelas, kemudian memiliki rhizome yang halus dengan bekas daun jelas menghitam dan ujung daun agak membulat. Dan untuk jenis Cymodocea rotundata yaitu tepi daun tidak bergerigi seludang daun menutup sempurna. Jenis lamun Enhalus ini mempunyai bentuk ukuran daun yang paling besar (daunnya bisa mencapai 1 meter) dan tumbu rambut pada rhizoma. Jenis Thalassia hemprichii ini merupakan lamun yang memiliki bentuk mirip Cymodocea rotundata tetapi rhizoma beruas-ruas dan tebal memiliki garis coklat pada helaian daun.

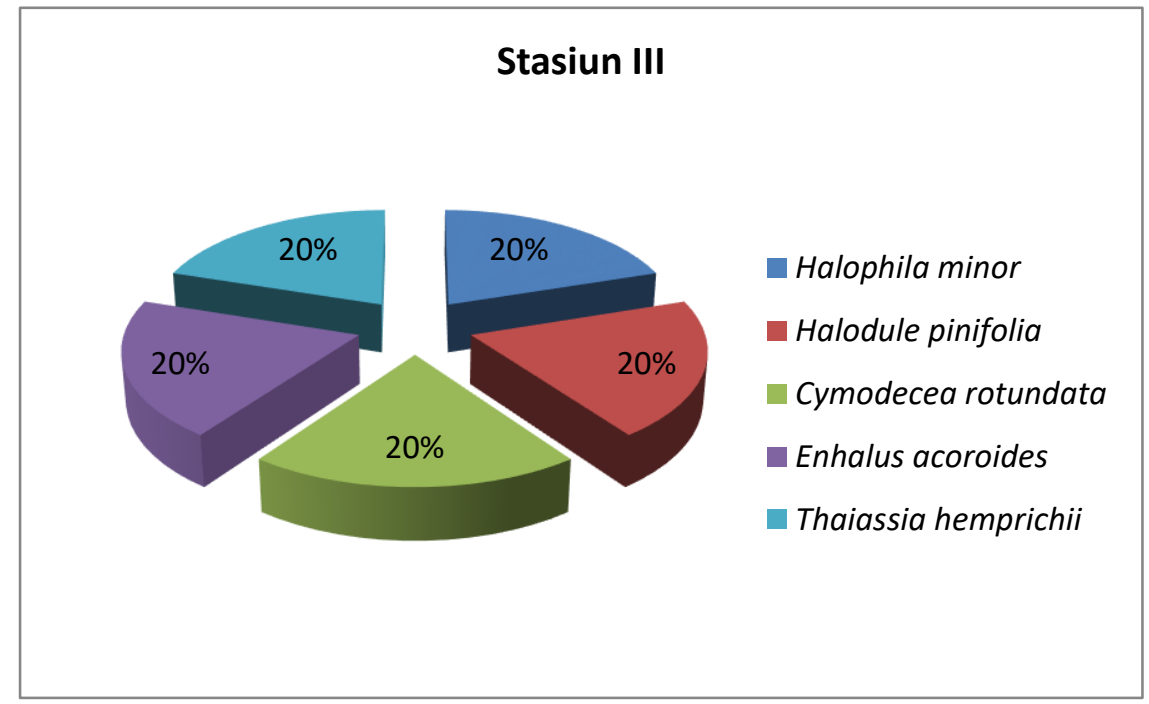

Gambar 4. Diagram jumlah komposisi jenis lamun pada stasiun III. 
Berdasarkan gambar 2, 3, dan 4 bahwa jumlah jenis dan jumlah individu komposisi jenis lamun yang di temukan di ke 3 stasiun cukup bervariasi. Komposisi jenis yang paling banyak di temukan yaitu pada stasiun III yaitu 5 jenis dengan jumlah total individu sebanyak 5 individu. Sementara itu terbanyak ke dua ditemukan pada stasiun II dengan jumlah sebanyak 3 jenis dengan total individu sebanyak 3 individu sedangkan stasiun I menempati urutan terakhir dengan 2 jenis dan 5 individu. Perbedaan jumlah jenis dan individu komposisi jenis lamun dari ke 3 stasiun pengamatan ini disebabkan karena perbedaan jenis persentase substrat yang berada di masing-masing stasiun pengamatan.

\section{Persentase Penutupan Lamun}

Persen tutupan lamun menggambarkan luas daerah yang tertutupi oleh lamun. Mengukur persen tutupan lamun merupakan suatu metode untuk melihat status dan untuk mendeteksi perubahan dari sebuah vegetasi (Hemminga dan Duarte, 2000). Hasil persentase tutupan lamun di berbagai stasiun ditampilkan pada (Gambar 5) dibawah ini.

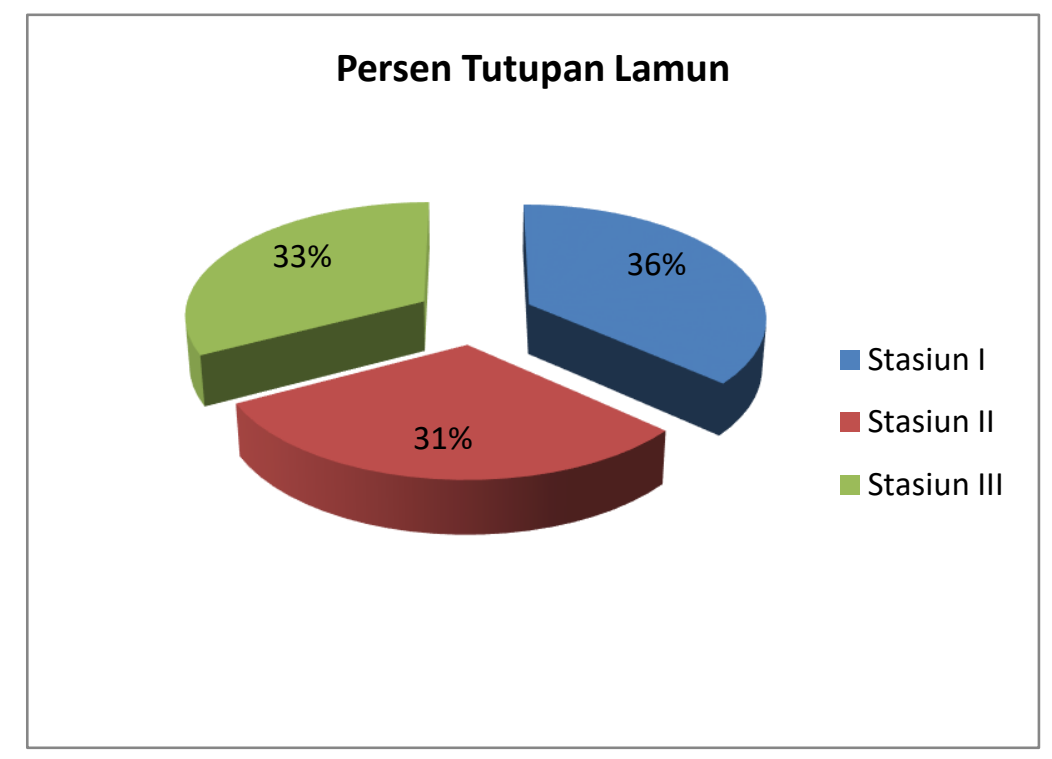

Gambar 5. Diagram jumlah Persen penutupan lamun.

Persen penutupan lamun tertinggi berada pada stasiun I sebesar $36 \%$ dan terendah pada stasiun II sebesar 31\%. Tingginya persen penutupan lamun di stasiun I dipengaruhi oleh tingginya kerapatan jenis lamun di stasiun ini. Telah dijelaskan sebelumnya bahwa, pada stasiun I merupakan habitat yang ideal bagi beberapa jenis lamun untuk tumbuh dan 
berkembang. Tingginya kerapatan jenis lamun Thalassia hemprichii dan Halophila minor menjadi alasan mengapa persen penutupan lamun di stasiun I menjadi lebih tinggi di bandingkan dengan stasiun II dan stasiun III.

\section{KESIMPULAN}

Berdasarkan hasil penelitian yang dilakukan, maka dapat disimpulkan sebagai berikut:

1. Hasil pengambilan data komposisi jenis lamun di lokasi Praktek Kerja Lapangan (PKL) dengan 3 stasiun pengamatan menunjukan bahwa ada perbedaan di mana yang tertinggi di temukan pada stasiun III sebanyak 5 jenis dengan jumlah 5 individu, kemudian yang tertinggi ke dua pada stasiun II ditemukan 3 jenis dengan jumlah 3 individu, sedangkan yang paling terendah yaitu pada stasiun I sebanyak 2 jenis dengan total 5 individu. Perbedaan jumlah jenis dan individu komposisi jenis lamun dari ke 3 stasiun pengamatan ini lebih disebabkan oleh perbedaan jenis persentasi substrat yang berada di masing-masing stasiun pengamatan.

2. Hasil yang di temukan persen penutupan lamun tertinggi berada pada stasiun I sebesar $36 \%$ dan terendah pada stasiun II sebesar 31\%. Tingginya persen penutupan lamun di stasiun I dipengaruhi oleh tingginya kerapatan jenis lamun di stasiun ini. Telah dijelaskan sebelumnya bahwa, pada stasiun I merupakan habitat yang ideal bagi beberapa jenis lamun untuk tumbuh dan berkembang. Tingginya kerapatan jenis lamun Thalassia hemprichii dan Halophila minor menjadi alasan mengapa persen penutupan lamun di stasiun I menjadi lebih tinggi di bandingkan dengan stasiun II dan stasiun III.

\section{DAFTAR PUSTAKA}

Bengen, DG. 2001. Sinopsis Ekosistem dan Sumber daya Pesisir dan Lamun. Institut pertanian Bogor. Bogor.

Brouns dan Heiji. 1991. Ekosistem padang lamun dengan fegetasi campuran. url (21 November 2018). 
Effendi, H. 2000. Telaah kualitas air. Managemen sumberdaya perairan. Fakultas perikanan dan ilmu kelautan. Insitut pertanian bogor. Bogor 259 hal.

Fachrul,M. F.,2007. Metode Sampling Bioekologi. PT Bumi Aksara :Jakrarta 208 Hal.

Hasanuddin,R., 2013. Hubungan Antara Kerapatan dan Morfometrik Lamun Enhalus acoroides Dengan Substrat dan Nutrien di Pulau Sarappo Lompo Kab. Pangkep.[Skripsi]. Universitas Hasanuddin.

Hemminga, M. A., dan Duarte. C. m. 2000. Seagrass Ecology. Cambridge: Cambridge University Press. Australia.

Hillman, K., D.J. Walker, A.W.D. Larkum, \& A.J. Mc Comb. 1989. Productivity and Nutrients Limitation on Seagrasses. Biology of Seagrasses. Netherland: Elsevier Science Publishers.

Kiswara, W. 1985. Habitat Dan Sebaran Geografik Lamun. Oseana 10(1): 21-30 pp.

Kiswara, W. 2004. Kondisi Padang Lamun (Seagrass) di Perairan Teluk Banten 1998-2001. Lembaga Penelitian Oseanografi, Lembaga Ilmu Pengetahuan Indonesia. Jakarta. Xii $+33 \mathrm{hml}$.

Laevastu T, Hayes ML. 1981. Fisheries oceano-graphy and ecology. Fishing News Books, London. Farnbarn-Surrey England. 199 p.

Merryanto, Y. 2000. Struktur Komunitas Ikan dan Asosiasinya Dengan Padang Lamun Perairan Teluk Awur Jepara. Tesis. Institut Pertanian Bogor. Bogor.

Nonji, A.,2005. Laut Nusantara. Djambatan. Jakarta. 368 Hal

Nontji, A. 1987. Laut Nusantara. Jakarta: Djambatan. Bengen, D.G. 2001. Ekosistem dan Sumberdaya Alam Pesisir Laut. Pusat Kajian Sumberdaya Pesisir dan Lautan IPB.

Odum, E. P. 1971. Fundamentals of ecology. W.B. Sounders Company Ltd., Philadelphia. 474p.

Reswara, T. A. 2010. Struktur Komunitas Lamun di Sekitar Kepulauan Seribu. Skripsi. FPIK. Universitas Padjadjaran.

Reswara, T. A. 2010. Struktur Komunitas Lamun di Sekitar Perairan Kepulauan Seribu. Skripsi. Fakultas Perikanan dan Ilmu Kelautan. Universitas Padjadjaran. Jatinangor.

Setyobudiandy, 1. Sulistiono., Kusmana., S. Hariyadi., A. Damar., A. Sembiring., dan Bahtiar. 2009. Sampling dan Analisis Data perikanan dan kelautan, terapan metode pengambilan dan contoh di wilayah pesisir dan laut. $312 \mathrm{pp}$. 
Wahab I, Madduppa H, Kawaroe M. 2017. Seagrass Species Distribution, Density, and Coverage at Panggang Island, Jakarta. IOP Conf. Series: Earth and Environmental Science, 54 012084. http://iopscience.iop. org/17 551315/54/1/012084. [2 September 2017].

Zulkifli. 2003. Pengelolaan dan pengembangan ekosistem padang lamun berwawasan lingkungan, berbasis masyarakat dan berkelanjutan bogor. Institut Pertanian Bogor. (1) : 7-11 Hlm. 